\title{
Asymmetric Mean Reversion in Low Liquid Markets: Evidence from BRVM
}

\author{
Nathaniel Gbenro ${ }^{1,2}$ (D) and Richard Kouamé Moussa ${ }^{2, *}$ \\ 1 Department of Economics, (Thema) University Cergy-Pontoise, 95011 Cergy-Pontoise, France; \\ nathaniel.gbenro@u-cergy.fr \\ 2 Ecole Nationale Supérieure de Statistique et d'Economie Appliquée, Abidjan 08, Côte d'Ivoire \\ * Correspondence: moussakr@gmail.com
}

Received: 31 December 2018; Accepted: 4 March 2019; Published: 6 March 2019

\begin{abstract}
This paper analyzes the mean reversion property on the west African stock market (in French, Bourse Régionale des Valeurs Mobilières BRVM). For this purpose, we use two daily indices: (i) the composite index (BRVMC) and (ii) the index of the 10 most liquid assets (BRVM10) collected from 3 January 2005 to 29 June 2018. We estimate an asymmetric nonlinear autoregressive model with an EGARCH innovation to account for heteroskedasticity. The results suggest the existence of a mean reversion property for both indices. The half-life time is 7 days for the composite index and 2 days for the BRVM 10 index. Furthermore, using a rolling regression technique, we show that the estimated half-life time declines slightly for the composite index.
\end{abstract}

Keywords: stock market efficiency; mean reversion; half-life; asymmetry; rolling regression

JEL Classification: C58; G14; G15

\section{Introduction}

The efficient market hypothesis (EMH) has been widely discussed in the literature related to financial markets. Introduced by Fama (1965), the EMH states that all the information about a stock is contained in the price. Three levels of efficiency can be identified in the literature with respect to the set of information that the prices contain: the strong, the semi-strong and the weak form. The main issue in the EMH, regardless of the level of efficiency, is the predictability of stock prices. If stock prices are predictable, then investors can implement a strategy to obtain excessive returns. In an efficient market, the stock prices are unpredictable (Narayan and Prasad 2007). An insight into this unpredictability is that the price follows a random walk process, i.e., the price is not stationary. Then, if the price is stationary, it implies that the price is predictable and the best prediction is the long-run average (Narayan and Prasad 2007; Wu and Lux 2018). In such a situation, the market is not efficient since investors can benefit from trading strategies based on a forecast of the future returns using the dynamics of the returns.

The majority of research conducted on this hypothesis focuses on developed stock markets in the United States and Europe (Ahmed et al. 2018; Palwasha et al. 2018; Poterba and Summers 1988; Spierdijk et al. 2012). Very few studies address the market efficiency in the context of African stock markets (Anoruo and Gil-Alana 2011; Kuttu 2018; Mlambo and Biekpe 2007). Among the latter, (Mlambo and Biekpe 2007) ${ }^{1}$ use a run test to show that the African markets (except those of Namibia, Botswana and

1 The markets studied in this paper are Egypt, Kenya, Zimbabwe, Morocco, Mauritius, Tunisia, Ghana, Namibia, Botswana and Côte d'Ivoire 
Kenya) have a significant number of stocks that do not fulfil the random walk assumption. This result implies that most of the African markets are not efficient ${ }^{2}$. To take into account the thin-trading characteristic of the African markets, Mlambo and Biekpe (2007) use the trade to trade price ratio and adjust for the number of days between two consecutive trading days.

Despite the interest in the EMH, many investors believe that one can make a profit from the times series of prices by focusing properly on some patterns in securities. One possible explanation behind that position is the theory of mean reversion (Palwasha et al. 2018). Mean reversion is the assumption that a stock's price will tend to move to the average price over time. This implies that the stock prices will return back to their long-run average values. The mean reversion theory is supported by three mains phenomena: the availability bias, the aversion to losses and the lower price preferences (Oikarinen and Schindler 2015; Tie and Zhang 2016). The EMH is contradictory to the mean reversion since one of the EMH's implications is that the changes in the price are completely random, i.e., it is impossible to forecast the pattern in the price. This is in line with the fact that the way a stock price behaved in the past does not affect how it will behave in the future. In practice, if the price follows a random walk process, then the market is efficient (weak form of efficiency).

Evidence for mean reverting stock prices has mainly been tested for several advanced and emerging stock markets (Ahmed et al. 2018; Fama 1965; Palwasha et al. 2018). Palwasha et al. (2018) find that the mean reversion theory is valid on the Pakistan stock market using daily data of three stock indices: KSE-100, LSE-25 and ISE-10. Further, the mean reversion rate shows that the indices do not have the same mean reversion speed. In the case of a high mean reversion speed, investors may make profits over a shorter period of time (for stock with a short rate of reversion). However, the investor who is willing to bear the risk of time may invest in stock which reverses slowly. A similar study has been conducted by Ahmed et al. (2018). They examine and compare the mean reversion phenomenon in developed and emerging stock markets and find that the mean reversion property is confirmed for both developed and emerging markets. They conclude that emerging markets exhibit higher returns in a shorter period of time. Furthermore, the mean reversion speed is higher in emerging markets than in developed ones.

Three approaches are commonly used in the literature to analyze the mean reversion property (Ahmed et al. 2018; Bali and Demirtas 2007; Narayan and Prasad 2007): (i) the Augmented Dickey-Fuller test (ADF), (ii) the AutoRegressive Conditional Heteroskedasticity (ARCH) and (iii) the Generalized AutoRegressive Conditional Heteroskedasticity model (GARCH). The ADF test gives insights into whether the prices or the returns are mean reverting. The ARCH and GARCH models are used to analyze deeply the mean reverting property and to estimate the half-life based on an estimated model that takes into account the persistence in the volatility of the returns. To analyze the mean reversion property, many authors use a linear model (Nam et al. 2006). However, the dynamics of the returns may be nonlinear. This nonlinearity is characterized by an asymmetric mean-reverting property. Corbet and Katsiampa (2018) use an asymmetric mean-reverting analysis framework to explore whether a cryptocurrency's returns exhibit such similar asymmetric reverting patterns. Using an asymmetric nonlinear autoregressive model (ANAR), they find evidence of a higher persistence of positive returns than negative returns which supports the existence of asymmetric reverting property. Similar results have been found by Nam et al. (2006).

While the mean reversion property has been analyzed in the US, the European and some emerging markets, little has been done on the west African stock market BRVM (Bourse régionale des valeurs mobilières). Indeed, Mlambo and Biekpe (2007) shows that, on the BRVM stock exchanges, the chances that one can detect patterns in the stock prices are not null. Therefore, it is important to analyze whether a mean reversion can be found on the BRVM stock exchanges. The overall aim of this study is to analyze the mean reversion property on the BRVM stock market using the main financial indices

2 It was the weak-form efficiency that was tested. 
(BRVMC and BRVM10). This study is important to the market regulator as well to investors. Indeed, investors can use the result to mitigate their strategy. This study is also relevant to the market regulator since it will allow a better understanding of the price discovery and the market stability.

The BRVM is the regional stock market for the eight countries of the West African Economic and Monetary Union (WAEMU), namely, Benin, Burkina Faso, Côte d'Ivoire, Guinea-Bissau, Mali, Niger, Senegal and Togo. The BRVM stock market is a frontier stock market created in September 1998. The expansion of its activities is very recent. In November 2001, the BRVM stock market started daily quotation and continuous quotation started in September 2013. Due to its rapid growth, the BRVM stock market was integrated into the MSCI, S\&P, and Dow Jones indices in June 2014. Moreover, the BRVM was integrated into the MISC frontier markets index in November 2016 and it is also recognized as a frontier market by S\&P, Russel and FTSE. The BRVM market is still tiny. In December 2018, the capitalization of the BRVM stock market was 12.85 billion euros. In total, 45 companies are listed on the BRVM market; more than 840 companies are listed on the Euronext Paris and more than 2000 on the NYSE markets. The share turnover is $30 \%$ in the BRVM market and $75 \%$ in the NYSE market. This recent and growing stock market with low capitalization offers the unique opportunity to analyze the mean reverting property on such a market.

In Section 2, we present an overview of the model and the estimation strategy. Section 3 presents the data and provides descriptive statistics on the sample. In Section 4 , the empirical findings are discussed and we conclude in Section 5.

\section{Model}

Before analyzing the mean reversion property on the BRVM financial market, we first check for the stationarity based on the Augmented Dickey-Fuller unit root test (ADF). If the series show no unit root, then we can use a stationary times series class model like covariance-stationary ARMA. This test is also an insight into the mean reversion property Palwasha et al. (2018). If the return has no unit root, then the returns may exhibit a mean reverting property. The ADF test is based on the estimation of the following equation:

$$
\Delta r_{t}=\text { type }_{i t}+\rho r_{t-1}+\sum_{j=1}^{p} \beta_{j} \Delta r_{t-j}+\epsilon_{t}
$$

where type $e_{i t}$ is either zero, a constant $\mu$ or a trend $\mu+\alpha t$. Those models are refereed to as type 1 (no intercept, no trend), type 2 (intercept and no trend) and type 3 (both intercept and trend) models (cf. Appendix C). The critical values used are those computed by Dickey and Fuller (1981).

To further investigate the mean reversion property on the BRVM market, we follow the approach used by Nam et al. (2006). Their model is an asymmetric nonlinear autoregressive model (ANAR). Denoting the return by $r_{t}$, the dynamics of the return is given by:

$$
\begin{aligned}
& r_{t}=\mu+\phi^{-} r_{t-1}+\epsilon_{t} \text { if } r_{t-1}<0 \\
& r_{t}=\mu+\phi^{+} r_{t-1}+\epsilon_{t} \text { if } r_{t-1} \geq 0
\end{aligned}
$$

where $\phi^{+}$is the return serial correlation prior to a positive return while $\phi^{-}$is the return serial correlation prior to a negative return. We will check the stationarity condition on $r_{t}$. This condition is equivalent to $\left|\phi^{+}\right|$and $\left|\phi^{-}\right|$are both less than one. Nam et al. (2006) argued that $\phi^{+}$and $\phi^{-}$have two interpretations. First, both are the reverting speed prior to a positive and a negative return, respectively. Also, it is expected that $\phi^{+}>\phi^{-}$, i.e., with the same magnitude, a negative return reverts, on average, more quickly than a positive return. The second interpretation is the fact that both parameters measure the relative reverting magnitude of a positive and a negative return. To estimate this asymmetric model, Equations (2) and (3) can be merged into a univariate first-order asymmetric nonlinear autoregressive model [ANAR(1)]. In this paper, we also test for the existence of a moving average component $[\operatorname{ANARMA}(1,1)]$ such that: 


$$
r_{t}=\mu+\left[\phi+\rho D_{1}\left(r_{t-1}<0\right)\right] r_{t-1}+\epsilon_{t}+\theta \epsilon_{t-1}
$$

where $D_{1}$ is a dummy variable, taking 1 if $r_{t-1}<0$ (the last period return is negative), and 0 otherwise. This model with $D_{1}$ is referred to as model 1 . To choose between ANAR(1) and ANARMA(1,1), we use the log-likelihood and the information criteria (Akaike Information Criterion, AIC (Akaike 1998); Hannan-Quinn Information Criterion, HQ (Hannan and Quinn 1979); Bayesian Information Criterion, BIC (Schwarz 1978); and Schwarz Information Criterion, SIC (Schwarz 1978)). If $\phi^{+}$is greater than $\phi^{-}$then $\rho<0$. Notice that if $\rho=0$, then the reverting pattern is symmetric and the nonlinear model is rejected. If $\rho<0$, it implies an asymmetric reverting pattern of stock returns. In such a situation, a negative return reverts more quickly than a positive one. We test for this asymmetric reverting property in Section 4.

We allow the asymmetric reverting patterns to incorporate different levels of consecutive price decreases through the analysis of the following model specification:

$$
r_{t}=\mu+\left[\phi+\rho D_{k}\left(r_{t-1}<0, \ldots, r_{t-k}<0\right)\right] r_{t-1}+\epsilon_{t}+\theta \epsilon_{t-1}
$$

where $D_{k}$ is a dummy variable, taking 1 if all $k$ prior returns are negative and 0 otherwise. The model with $D_{k}$ is referred to as model $k$. Based on the summary statistics in Table 2, we choose to estimate the models with $k$ between 1 and 3 .

Conditional heteroskedasticity is a well-known property of the stock returns. Empirical models that have been frequently used to capture the heteroskedasticity are the family of ARCH and GARCH models introduced by Engle (1982) and Bollerslev (1986), respectively. To account for the heteroskedasticity in the return dynamics in this paper, we use the exponential GARCH model (Corbet and Katsiampa 2018; Nam et al. 2006). This model allows to capture the leverage effects. Other alternatives are the standard GARCH (sGARCH) model (Palwasha et al. 2018). However, the advantage of using the EGARCH model is that it specifies the logarithm of conditional volatility and avoids the need for any parametric constraints, so any positivity restrictions on parameters to ensure non-negativity of $h_{t}$ is not needed. The exponential GARCH(p,q) model is given by (Nelson 1991):

$$
\log \left(h_{t}\right)=\omega+\sum_{i=1}^{p} \beta_{i} \log \left(h_{t-i}\right)+\sum_{j=1}^{q}\left[\alpha_{j} v_{t-j}+\gamma_{j}\left(\left|v_{t-j}\right|-E\left|v_{t-j}\right|\right)\right]
$$

where $h_{t}=\sigma_{t}^{2}$ is the conditional variance of $\epsilon_{t}$ and $v_{t}$ is the standardized residual, i.e., $v_{t}=\frac{\epsilon_{t}}{\sqrt{h_{t}}}$. The term $\gamma_{j}\left(\left|v_{t-j}\right|-E\left|v_{t-j}\right|\right)$ represents the magnitude effect and $\alpha_{j} v_{t-j}$ the sign effect of the standardized residual on the conditional variance. The magnitude effect can be thought of as capturing the volatility clustering, and the sign effect as capturing the asymmetric effect of return shocks on volatility.

One important feature of those models is the fact that they allow the persistence of a shock to be computed. Thus, the persistence in an EGARCH model is related to the rate of decaying of large volatilities after a shock. The persistence parameter in the EGARCH model is defined as $\hat{P}=\sum_{i=1}^{p} \beta_{i}$. If the persistence parameter is less than 1 , then the return series exhibit mean reversion. However, if the persistence parameter is equal to 1 , then the series follow the random walk. Another related concept is the half-life (h2l) parameter. The latter is defined as the period that it takes the returns to reach half the long-term average values. The half-life is given by:

$$
h 2 l=\frac{-\log (2)}{\log (\hat{P})}
$$

We use EGARCH(1,1) since with $(1,1)$ as lags, it is possible to give an accurate description of the conditional variance (Engle 2001). This specification has been widely used in the literature to deal with mean reversion (Ahmed et al. 2018; Kuttu 2018; Nam et al. 2006; Palwasha et al. 2018). 


\section{Data and Summary Statistics}

Data used herein are daily return series for the main BRVM indexes (BRVMC and BRVM10). These data are collected from 3 January 2005 to 29 June 2018. The BRVM composite index (BRVMC) is the main index of the BRVM financial market. It includes all the assets which are traded on this market while the BRVM10 index only includes the 10 most liquid assets. The data have been collected from the BRVM's website. It is worth noting that the BRVM financial market is closed on Saturday and Sunday. All the return series are computed as a percentage of the returns (see Appendix A for the dynamics of the time series).

Table 1 provides the BRVMC and the BRVM10 daily returns statistics. For the BRVMC, the average return is $4 \times 10^{-4}$ while the standard deviation is $9 \times 10^{-3}$. The same values hold for the BRVM 10 daily return.

Table 1. Summary statistics on the BRVMC and BRVM10 returns.

\begin{tabular}{lccccccc}
\hline Indices & $\mathbf{N}$ & Mean & St. Dev. & Min & Pctl(25) & Pctl(75) & Max \\
\hline BRVMC returns & 3299 & 0.0004 & 0.0087 & -0.0879 & -0.003 & 0.004 & 0.0951 \\
BRVM10 returns & 3299 & 0.0002 & 0.0105 & -0.1045 & -0.0040 & 0.0042 & 0.0848 \\
\hline
\end{tabular}

Pctl(25) and Pctl(75) denote respectively the 25th and the 75th percentiles.

Table 2 reports the number of consecutive returns with the same sign between two and sixteen consecutive periods. We find that for both the BRVMC and BRVM10 indices, the number of negative returns declines slightly and is smaller than the number of positive returns (these results are consistent with the literature Corbet and Katsiampa (2018)). These results suggest an asymmetric reverting behavior between positive and negative returns, with negative returns reverting more quickly than positive ones. An alternative explanation is that in a rising market one would expect more positive returns than negative returns. To confirm the mean reversion property, the parameter $\phi$ in the model should be significantly different from zero, while the asymmetric reversion property is verified when the parameter $\rho$ is negative and significantly different from zero. We test for this asymmetric mean reversion property in Section 4.

Figure A3 in Appendix B gives the lag lengths to be considered for the autoregressive part of the model. The lags 1, 4, 5 and 6 are those to be considered for both BRVMC and BRVM10 indexes. We estimated the models with each of these lags and selected the best models based on the log likelihood value and the information criteria (see Table A1 in Appendix B). The model with lag 1 has been selected for both BRVMC and BRVM10 returns. In Table 3, we compare the information criteria and the log-likelihood for two models: ANAR(1) and ANARMA(1,1) using the D1 dummy variable. These comparisons are made for the BRVMC and the BRVM10 indices. We find that the ANARMA $(1,1)$ model has the highest log-likelihood (LL) and the lowest information criteria (AIC, BIC, HQ, SIC) for both series (BRVMC and BRVM10). Therefore, in Section 4, we estimate an ANARMA(1,1) model for these series of returns. 
Table 2. Consecutive returns with the same sign.

\begin{tabular}{ccccc}
\hline & \multicolumn{2}{c}{ BRVMC Return } & \multicolumn{2}{c}{ BRVM10 Return } \\
\hline & + & - & + & - \\
\hline $2 \mathrm{c}$ & 426 & 356 & 409 & 373 \\
$3 \mathrm{c}$ & 232 & 176 & 214 & 179 \\
$4 \mathrm{c}$ & 117 & 101 & 103 & 89 \\
$5 \mathrm{c}$ & 62 & 64 & 64 & 49 \\
$6 \mathrm{c}$ & 42 & 33 & 45 & 28 \\
$7 \mathrm{c}$ & 22 & 20 & 28 & 21 \\
$8 \mathrm{c}$ & 15 & 12 & 19 & 11 \\
$9 \mathrm{c}$ & 11 & 6 & 11 & 6 \\
$10 \mathrm{c}$ & 9 & 2 & 7 & 1 \\
$11 \mathrm{c}$ & 5 & 1 & 4 & 0 \\
$12 \mathrm{c}$ & 4 & 1 & 4 & 0 \\
$13 \mathrm{c}$ & 3 & 0 & 2 & 0 \\
$14 \mathrm{c}$ & 3 & 0 & 2 & 0 \\
$15 \mathrm{c}$ & 1 & 0 & 0 & 0 \\
$16 \mathrm{c}$ & 1 & 0 & 0 & 0 \\
\hline
\end{tabular}

Table 3. Log-likelihood and information criteria for model selection.

\begin{tabular}{lcccc}
\hline & \multicolumn{2}{c}{ BRVMC } & \multicolumn{2}{c}{ BRVM10 } \\
\hline Criteria & ANAR & ANARMA & ANAR & ANARMA \\
\hline LL & 11,222 & 11,255 & 10,481 & 10,496 \\
AIC & -6.800 & -6.820 & -6.350 & -6.360 \\
BIC & -6.790 & -6.800 & -6.340 & -6.340 \\
HQ & -6.790 & -6.810 & -6.350 & -6.350 \\
SIC & -6.800 & -6.820 & -6.350 & -6.360 \\
\hline
\end{tabular}

\section{Estimation Results}

\subsection{Mean Reversion on the Overall Sample}

Table 4 presents the estimation results of the ANARMA(1,1) and ANAR(1) models for both the BRVMC and BRVM10 returns. As stated in Section 2, the serial correlation is captured by $\phi+$ $\rho D_{1}\left(r_{t-1}<0\right)$ while the asymmetric reverting behavior is measured by $\rho$. We find that the asymmetric model is validated for the two series of returns. As expected, the parameter $\rho$ is negative and statistically significant at the $0.1 \%$ level for the two models. This suggests a strong reverting behavior of negative returns in terms of the reverting speed and magnitude.

In addition, the return serial correlation is measured by $\phi$ after a positive return or by $\phi+\rho$ after a negative return. Estimates show that $\phi$ is positive and statistically significant at the 0.1 percent level for the two models. Furthermore, the magnitude effect, captured by $\gamma$, which captures the volatility clustering, is significantly different from zero for all models. Contrariwise, the sign effect $(\alpha)$ which captures the asymmetric effect of return shocks on volatility is significantly different from zero for the BRVMC return only.

Table 5 displays the mean reversion speed in the last line. The half-life is computed using Equation (7). The BRVMC return takes 7 days to revert back to half of its mean and the BRVM10 return takes around 2 days. This result suggests that short-term investors should invest in the stock of the BRVM10 index while long-term investors should invest in all others stock.

To confirm the asymmetric reverting patterns, we include two and three consecutive price decreases in the model (see Equation (5)). In these models, if $\rho$ remains negative, it confirms a strong reverting pattern of the negative returns. In the case where $\rho$ is neither null nor positive, this lead to a weak form of the asymmetric mean reversion pattern. The estimates for models with 
$k=2$ and $k=3$ should provide important information on the source of the asymmetric mean-reverting behavior of the stock returns. According to Nam et al. (2006) and Nam et al. (2001), if the time-varying rational expectation is a relevant explanation of the asymmetry, then the parameter $\rho$ will be negative and significantly different from zero. Otherwise, the market overreaction is the right explanation.

Table 4. Estimated parameters for the models and half-life.

\begin{tabular}{lcc}
\hline Parameters & BRVMC & BRVM10 \\
\hline$\mu$ & $0.00^{* *}$ & $-0.00^{* *}$ \\
& $(0.00)$ & $(0.00)$ \\
& $0.98^{* * *}$ & $0.91^{* * *}$ \\
$\theta$ & $(0.01)$ & $(0.01)$ \\
& $-0.93^{* * *}$ & $-0.87^{* * *}$ \\
$\rho$ & $(0.00)$ & $(0.01)$ \\
& $-0.12^{* * *}$ & $-0.19^{* * *}$ \\
$\omega$ & $(0.02)$ & $(0.03)$ \\
& $-0.87^{* * *}$ & $-2.88^{* *}$ \\
$\alpha$ & $(0.09)$ & $(0.97)$ \\
$\beta$ & $0.04^{*}$ & -0.01 \\
& $(0.02)$ & $(0.03)$ \\
$\gamma$ & $0.911^{* * *}$ & $0.68^{* * *}$ \\
$\gamma$ & $(0.01)$ & $(0.11)$ \\
& $0.23^{* * *}$ & $0.26^{* * *}$ \\
\hline Half-life $(\mathrm{h} 2 \mathrm{l})$ & 7.05 days & 1.8 days \\
\hline \multirow{2}{*}{$* * * p<0.001, * * p<0.01, * p<0.05}$.
\end{tabular}

Table 5. Models with two and three consecutive price decreases.

\begin{tabular}{|c|c|c|c|c|c|c|}
\hline \multirow{2}{*}{ Parameters } & \multicolumn{3}{|c|}{ BRVMC } & \multicolumn{3}{|c|}{ BRVM10 } \\
\hline & Model 1 & Model 2 & Model 3 & Model 1 & Model 2 & Model 3 \\
\hline \multirow[t]{2}{*}{$\mu$} & $0.00^{* *}$ & $0.00^{* * *}$ & 0.00 & $-0.00 * *$ & 0.00 & $0.00^{* * *}$ \\
\hline & $(0.00)$ & $(0.00)$ & $(0.00)$ & $(0.00)$ & $(0.00)$ & $(0.00)$ \\
\hline \multirow[t]{2}{*}{$\phi$} & $0.98^{* * *}$ & $-0.11^{* * *}$ & $-0.06^{*}$ & $0.91^{* * *}$ & -0.18 & $-0.14^{*}$ \\
\hline & $(0.01)$ & $(0.02)$ & $(0.03)$ & $(0.01)$ & $(0.31)$ & $(0.07)$ \\
\hline \multirow[t]{2}{*}{$\theta$} & $-0.93^{* * *}$ & $0.04^{* * *}$ & 0.00 & $-0.87^{* * *}$ & 0.15 & 0.10 \\
\hline & $(0.00)$ & $(0.01)$ & $(0.01)$ & $(0.01)$ & $(0.25)$ & $(0.06)$ \\
\hline \multirow[t]{2}{*}{$\rho$} & $-0.12^{* * *}$ & $0.17^{*}$ & 0.22 & $-0.19^{* * *}$ & -0.02 & 0.05 \\
\hline & $(0.02)$ & $(0.07)$ & $(0.16)$ & $(0.03)$ & $(0.29)$ & $(0.06)$ \\
\hline \multirow[t]{2}{*}{$\omega$} & $-0.87^{* * *}$ & $-0.85^{* * *}$ & -0.84 & $-2.88^{* *}$ & $-2.83^{* *}$ & -2.81 ** \\
\hline & $(0.09)$ & $(0.02)$ & $(1.55)$ & $(0.97)$ & $(1.00)$ & $(0.96)$ \\
\hline \multirow[t]{2}{*}{$\alpha$} & $0.04 *$ & 0.04 & 0.05 & -0.01 & -0.01 & -0.01 \\
\hline & $(0.02)$ & $(0.02)$ & $(0.14)$ & $(0.03)$ & $(0.03)$ & $(0.03)$ \\
\hline \multirow{2}{*}{$\beta$} & $0.91^{* * *}$ & $0.91^{* * *}$ & $0.91^{* * *}$ & $0.68^{* * *}$ & $0.69^{* * *}$ & $0.69^{* * *}$ \\
\hline & $(0.01)$ & $(0.00)$ & $(0.19)$ & $(0.11)$ & $(0.11)$ & $(0.11)$ \\
\hline \multirow[t]{2}{*}{$\gamma$} & $0.23^{* * *}$ & $0.21^{* * *}$ & 0.21 & $0.26^{* * *}$ & $0.26^{* * *}$ & $0.26^{* * *}$ \\
\hline & $(0.04)$ & $(0.04)$ & $(1.50)$ & $(0.05)$ & $(0.05)$ & $(0.05)$ \\
\hline LL & $11,255.22$ & $11,227.17$ & $11,227.18$ & $10,495.79$ & $10,479.01$ & $10,479.31$ \\
\hline AIC & -6.82 & -6.80 & -6.80 & -6.36 & -6.35 & -6.35 \\
\hline $\mathrm{BIC}$ & -6.80 & -6.79 & -6.79 & -6.34 & -6.33 & -6.33 \\
\hline SIC & -6.82 & -6.80 & -6.80 & -6.36 & -6.35 & -6.35 \\
\hline HQ & -6.81 & -6.80 & -6.80 & -6.35 & -6.34 & -6.34 \\
\hline
\end{tabular}

Table 5 shows the results of the estimation of the model with $k=1,2$ and 3 . We find that the asymmetric mean reversion is weak since $\rho$ is not negative in models with $k=2$ and $k=3$. Then, 
the time-varying rational expectation is not a relevant explanation for the asymmetry. In such a situation, the market overreaction can be the relevant explanation.

\subsection{Dynamics of Mean Reversion}

The BRVM stock market has expanded rapidly since its creation. In addition, since 2012, one of the most important countries in the region, Côte $\mathrm{d}^{\prime}$ Ivoire, is experiencing rapid growth with an annual growth rate of $8 \%$. The stock market capitalization grew from 9.46 billion euros in September 2014 to 12.85 billion euros in December 2018. These variations stress the issue of a non-constant mean reversion speed. The literature highlights the non-constant mean reversion property in the case of structural break (Rapach and Wohar 2006) or crisis (Poterba and Summers 1988). Then, to account for the dynamics of the mean reversion speed, we use a rolling regression approach (Spierdijk et al. 2012).

The rolling regression scheme consists of estimating the model on some sub-samples of the overall sample, called windows. The subsamples are moved with regular and consecutive steps in order to cover the whole sample. In this paper, we apply two different schemes of rolling regression. The first one is the standard rolling regression. For a standard rolling regression with a 2-year window and 1-month steps, the subsample for the first regression will start from 3 January 2005 to 31 December 2006. Then, for the second regression, the subsample will start from 1 February 2005 to 31 January 2007 , and so one. The second scheme we studied is the recursive rolling regression scheme. It consists of starting with a subsample of 2 years and at each estimation, we increase the sample by 1 month. In this scheme, the starting date is fixed and the end date moves forward so that the last regression is the regression on the overall sample. The latter scheme has the advantage of accounting for the whole history while estimating the model. It also allows to understand how the mean reversion speed has varied over time to reach its current value. The former scheme has the advantage of giving an estimate of the speed of the mean reversion only using the short-term history. The two analyses are complementary, giving a better understanding of the mean reversion process.

It is shown in the literature that the choice of the window is critical (Spierdijk et al. 2012). When the window is very small, it weakens the estimates and leads to very volatile estimates of the mean reversion speed. However, too large windows lead to smoothed estimates of the speed of the mean reversion. In the local context, choosing a large window may also lead to low precision of the estimated speed of the mean reversion. This is essentially due to structural changes of the BRVM financial market. Thus, to capture these effects, we provide estimations of the mean reversion speed using 2, 4, 6 and 8 years as windows.

Results from the two schemes of rolling regression are provided in appendix ${ }^{3}$. For the BRVMC index, results using recursive rolling regression with a 2-year window suggest that for windows ending before 2015, the half-life fluctuates over 8 days. However, for windows ending after 2015, the half-life seems to be stable around 7 days (see Figure 1a). This result remains the same for all four windows we tested (see Figure A4 in Appendix D). However, using a standard rolling regression with a 2-year window leads to erratic half-life estimates (see Figure 1b). Increasing the window leads to more accurate half-life estimates. For a 4-year window, the half-life fluctuates between 2 and 6 days after January 2014 while it varies between 2 and 4 days after July 2016 with a 6-year window and between 2 and 4 days after June 2015 with an 8-year window (see Figure A5 in Appendix D). Combining the results from the two rolling regression schemes, it clearly appears that the half-life for the BRVMC index is decreasing over time. On average, the half-life was 9.05 days in the period

3 Appendix D provides the dynamics of the half-life for both BRVMC and BRVM10 indices using each of the four windows considered for each of the two schemes of rolling regression. In Appendix E, the dynamics of the persistence parameter (EGARCH coefficient) is plotted for both BRVMC and BRVM10 indices under the two schemes and for all four windows. The dynamics for all other coefficients of the models using the rolling regression under the two schemes and for all the windows are available upon request to the authors. 
of daily quotation (before September 2013) and was 3.4 days in the period of continuous quotation (after September 2013).

For the BRVM10 index, the estimated half-life using recursive rolling with a 2-year window (see Figure 1c) fluctuates for windows ending before January 2012. Between 2012 and January 2017, the half-life was around 1.4 days and increased to 1.8 days after July 2017. However, using a standard rolling regression, the half-life does not seem to be stable. However, on average, the half-life was 1.4 day in the period of daily quotation and reached 3.5 days in the period of continuous quotation.

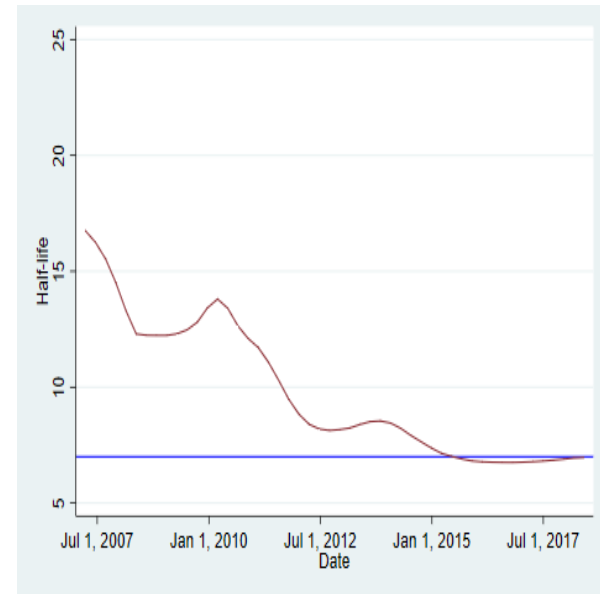

(a)

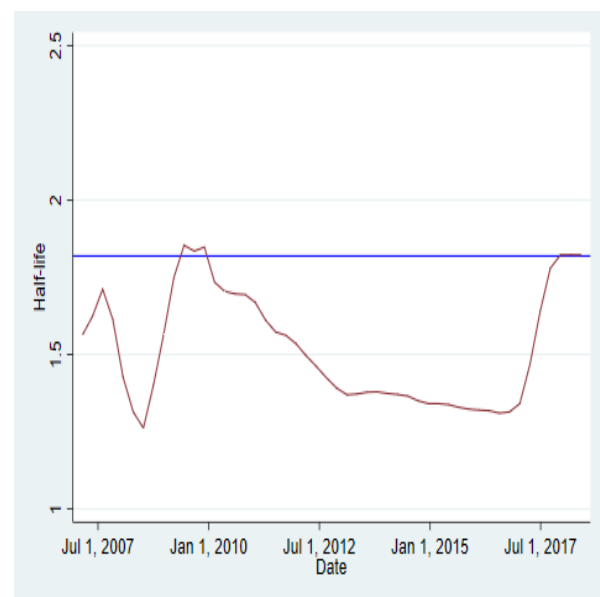

(c)

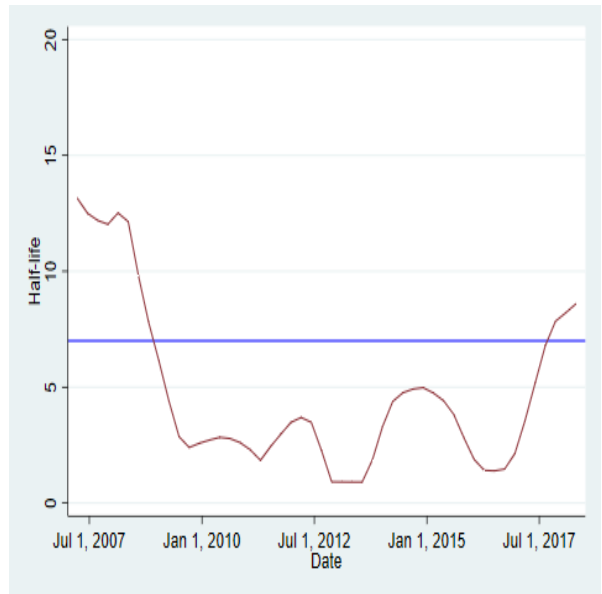

(b)

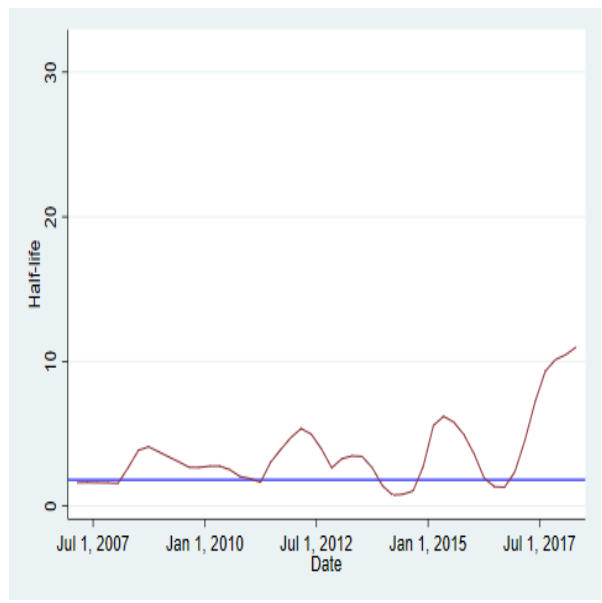

(d)

Figure 1. Dynamics of half-life for BRVM indices using rolling regression. These graphs plot the half-life estimated using rolling regression. The date is the end date for a selected window. In (a), the half-time is 14 days at the beginning using recursive rolling regression with a window whose end date is 1 July 2007. (a) Dynamics of the BRVMC half-time using recursive rolling regression with a 2-year window; (b) Dynamics of the BRVMC half-time using standard rolling regression with a 2-year window; (c) Dynamics of the BRVM10 half-time using recursive rolling regression with a 2-year window; (d) Dynamics of the BRVM10 half-time using standard rolling regression with a 2-year window.

\section{Conclusions}

This paper aims at analyzing the asymmetric property of mean reversion on the BRVM stock market. To reach this goal, we use a nonlinear autoregressive moving average model. By allowing an 
EGARCH innovation, it has been possible to compute and compare the mean reversion speed of the BRVM main indices. The study results indicate that the two main indices of the BRVM stock market show a significant mean reversion process. This implies that the returns of those stocks revert back to their long-term mean after a certain period of time. Further, to analyze the mean reversion speed, we use the half-life method. The half-life method helps to calculate the period of time that it takes the returns to reach half the long-term average values. The study results show that the returns of the BRVM10 revert back to half of their previous value after 2 days, whereas, for the BRVMC, they revert back after 7 days. One implication of these results is that, for a short-term investment, it is better to invest in the BRVM10 index.

We find that the asymmetric mean reversion is weak, since the parameter $\rho$ does not remain negative when we include two or three consecutive returns of the same sign in the model. This provides important information on the source of the asymmetric mean reverting behavior of stock returns. This finding suggests that the market overreaction can be a relevant explanation for the asymmetric mean reversion. Investors do not react in the same manner to information about the prices. If the available information makes the prices decline, investors overreact to the news. Then, the stock becomes oversold until it returns to its intrinsic value. The same interpretation holds when the available information makes the prices increase. In such a situation, investors can take advantage of the overreaction by buying stocks for which the prices have decreased due to bad information.

As the literature highlights that the mean reversion property is not constant, because of structural break or crisis, we use a rolling regression approach to assess the stability of the mean reversion speed. We find that the mean reversion speed of the BRVMC returns declines slightly over the sample period. This suggests that the BRVM market becomes more efficient over time.

Author Contributions: The authors have contributed jointly to all of the sections of the paper.

Funding: This research received no external funding.

Acknowledgments: The authors are grateful to Aboudou OUATTARA for giving access to the data. The authors are also grateful to Désiré KANGA for his helpful comments on an earlier version of the paper.

Conflicts of Interest: The authors declare no conflicts of interest.

\section{Appendix A. The BRVM Main Indices}

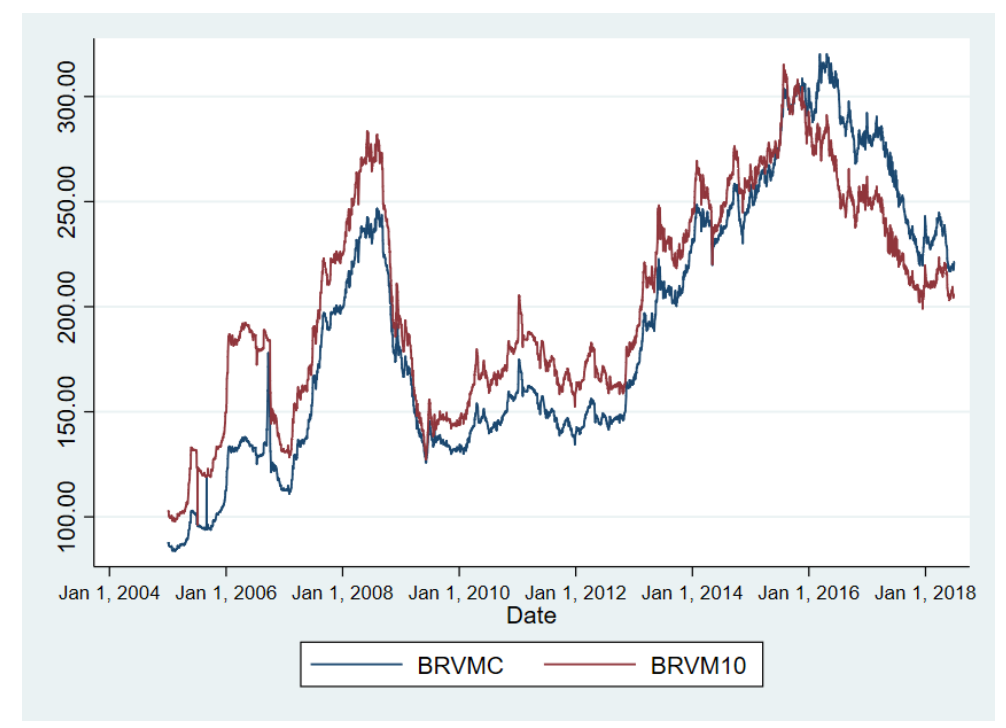

Figure A1. Dynamics of the daily BRVMC and the BRVM 10 indices. 


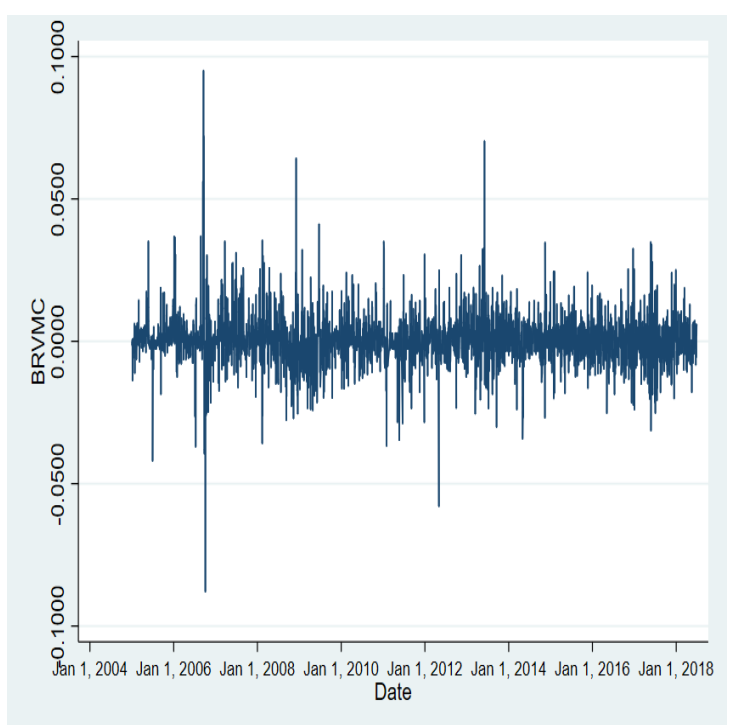

(a)

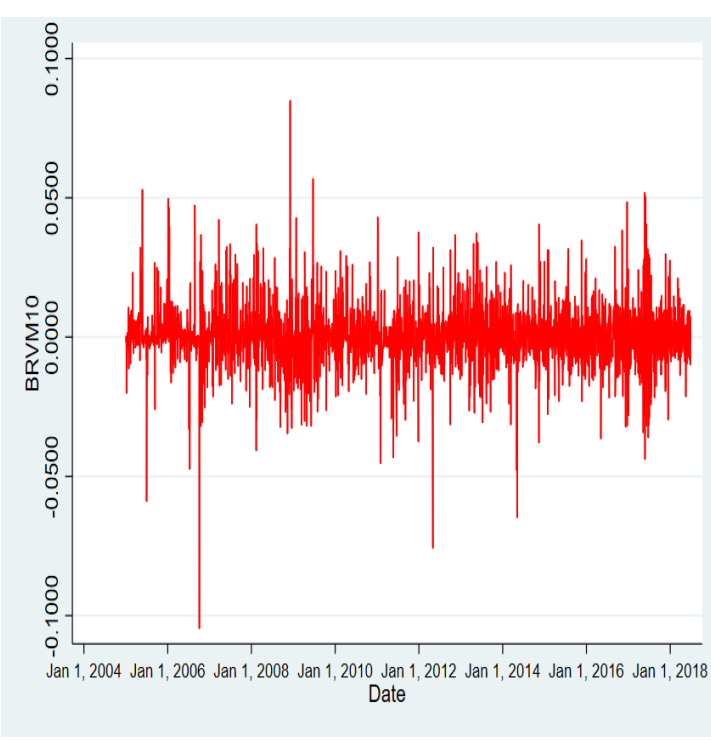

(b)

Figure A2. Dynamics of the returns for the BRVMC and BRVM10. (a) Dynamics of the BRVMC returns; (b) Dynamics of the BRVM10 returns.

\section{Appendix B. Correlogram}

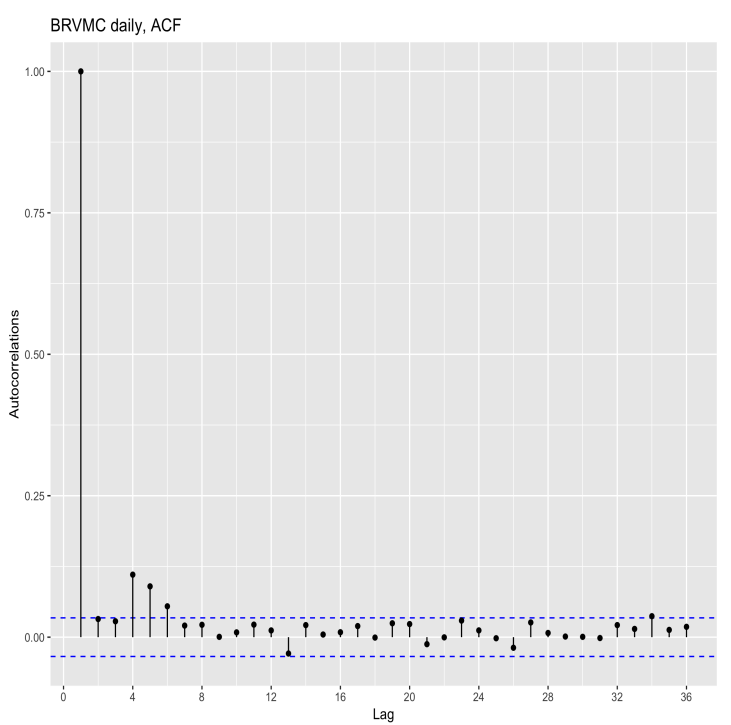

(a)

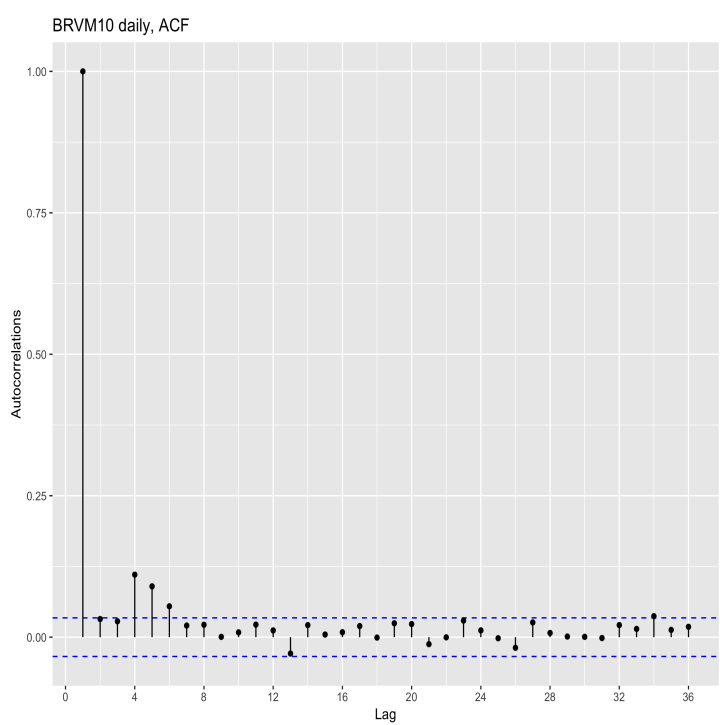

(b)

Figure A3. Correlogram of the BRVMC and BRVM10 returns. (a) Correlogram of the BRVMC; (b) Correlogram of the BRVM10. 
Table A1. Information criteria for model selection.

\begin{tabular}{lcccccccc}
\hline \multicolumn{7}{c}{ BRVM C } \\
\hline & Lag 1 & Lag 4 & Lag 5 & Lag 6 & Lag 1 & Lag 4 & Lag 5 & Lag 6 \\
\hline LL & $11,255.22$ & $11,243.42$ & $11,276.25$ & $11,277.33$ & $10,495.79$ & $10,490.59$ & $10,493.63$ & $10,531.81$ \\
AIC & -6.82 & -6.81 & -6.82 & -6.82 & -6.36 & -6.35 & -6.35 & -6.37 \\
BIC & -6.80 & -6.77 & -6.79 & -6.78 & -6.34 & -6.32 & -6.31 & -6.33 \\
SIC & -6.82 & -6.81 & -6.82 & -6.82 & -6.36 & -6.35 & -6.35 & -6.37 \\
HQ & -6.81 & -6.79 & -6.81 & -6.81 & -6.35 & -6.34 & -6.34 & -6.36 \\
\hline
\end{tabular}

\section{Appendix C. Stationary Test}

Table A2. Unit root tests (ADF) on the return series.

\begin{tabular}{lcccccc}
\hline Lag & \multicolumn{2}{c}{ Type 1 } & \multicolumn{2}{c}{ Type 2 } & \multicolumn{2}{c}{ Type 3 } \\
\hline & ADF & $p$-Value & ADF & $p$-Value & ADF & $p$-Value \\
\hline \multicolumn{7}{c}{ BRVMC return } \\
\hline 0 & -55.513 & 0.010 & -55.597 & 0.010 & -55.664 & 0.010 \\
1 & -38.768 & 0.010 & -38.857 & 0.010 & -38.928 & 0.010 \\
2 & -28.747 & 0.010 & -28.830 & 0.010 & -28.897 & 0.010 \\
3 & -23.596 & 0.010 & -23.677 & 0.010 & -23.742 & 0.010 \\
4 & -20.827 & 0.010 & -20.911 & 0.010 & -20.980 & 0.010 \\
5 & -19.498 & 0.010 & -19.586 & 0.010 & -19.660 & 0.010 \\
6 & -18.429 & 0.010 & -18.522 & 0.010 & -18.601 & 0.010 \\
7 & -17.854 & 0.010 & -17.953 & 0.010 & -18.037 & 0.010 \\
8 & -17.070 & 0.010 & -17.174 & 0.010 & -17.262 & 0.010 \\
\hline \multicolumn{7}{c}{} \\
& & & BRVM10 return & & \\
\hline 0 & -58.345 & 0.010 & -58.367 & 0.010 & -58.419 & 0.010 \\
1 & -40.131 & 0.010 & -40.157 & 0.010 & -40.214 & 0.010 \\
2 & -30.613 & 0.010 & -30.640 & 0.010 & -30.697 & 0.010 \\
3 & -25.351 & 0.010 & -25.378 & 0.010 & -25.435 & 0.010 \\
4 & -21.540 & 0.010 & -21.569 & 0.010 & -21.630 & 0.010 \\
5 & -20.183 & 0.010 & -20.214 & 0.010 & -20.279 & 0.010 \\
6 & -19.874 & 0.010 & -19.909 & 0.010 & -19.982 & 0.010 \\
7 & -18.599 & 0.010 & -18.635 & 0.010 & -18.712 & 0.010 \\
8 & -16.970 & 0.010 & -17.006 & 0.010 & -17.083 & 0.010 \\
\hline
\end{tabular}




\section{Appendix D. Dynamics of Half-Time}

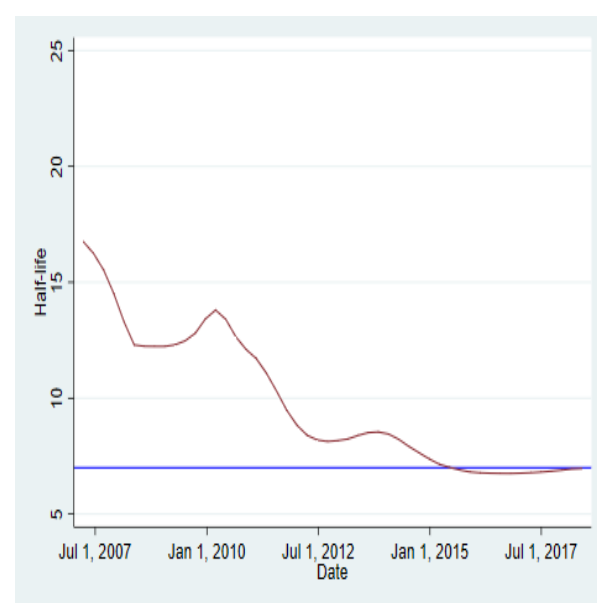

(a)

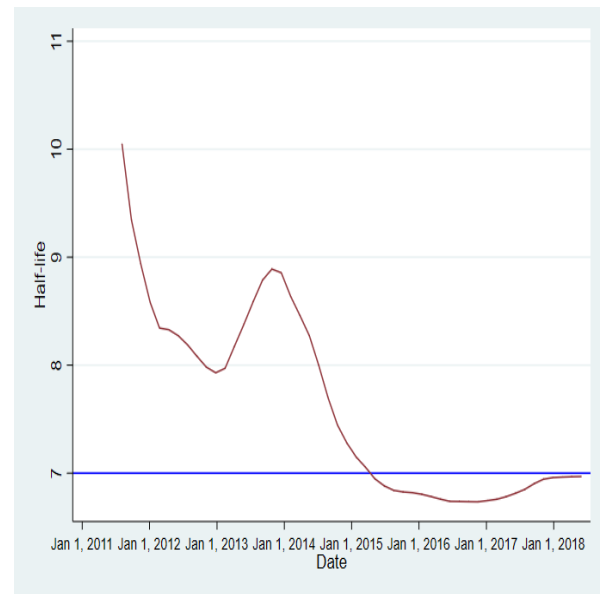

(c)

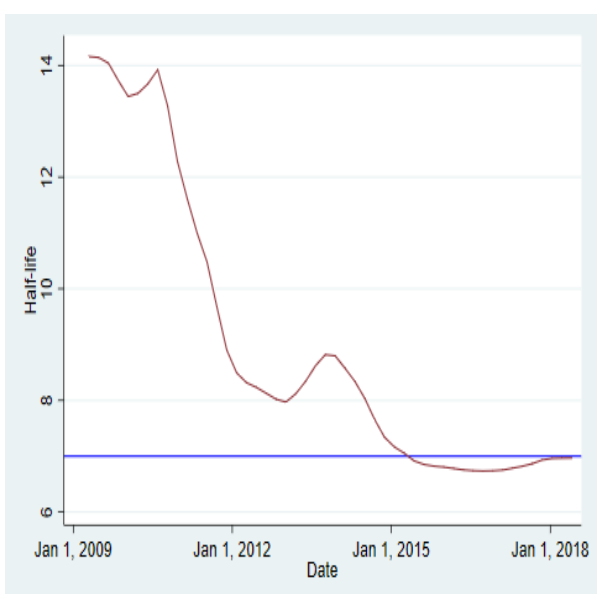

(b)

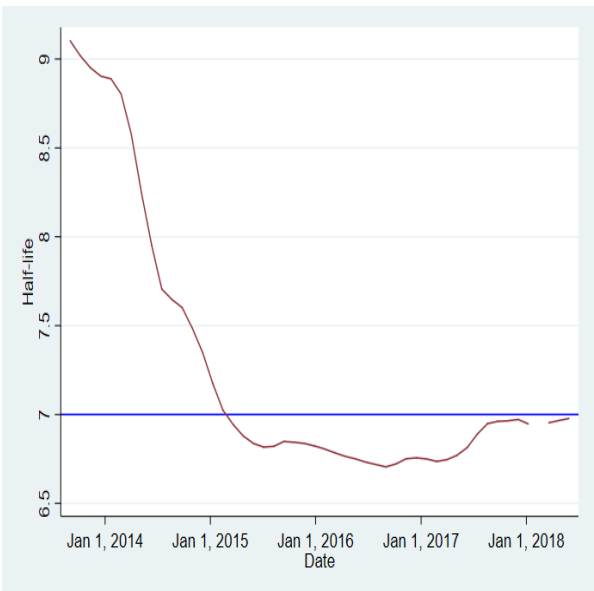

(d)

Figure A4. Dynamics of half-time for the BRVMC index using recursive rolling regression. These graphs plot the half-time estimated using rolling regression. The date is the end date for a selected window. In (a), the half-time is 14 days using recursive rolling regression with a window whose end date is 1 July 2007. (a) Dynamics of half-time for the BRVMC index using recursive rolling regression with a 2-year window; (b) Dynamics of half-time for the BRVMC index using recursive rolling regression with a 4-year window; (c) Dynamics of half-time for the BRVMC index using recursive rolling regression with a 6-year window; (d) Dynamics of half-time for the BRVMC index using recursive rolling regression with an 8-year window. 


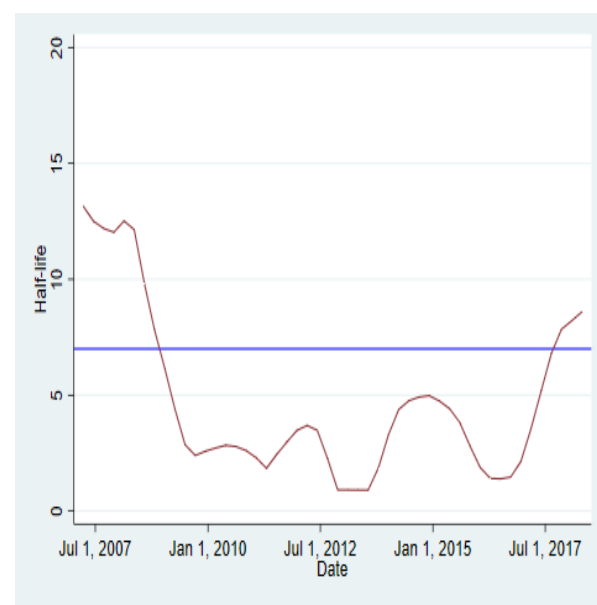

(a)

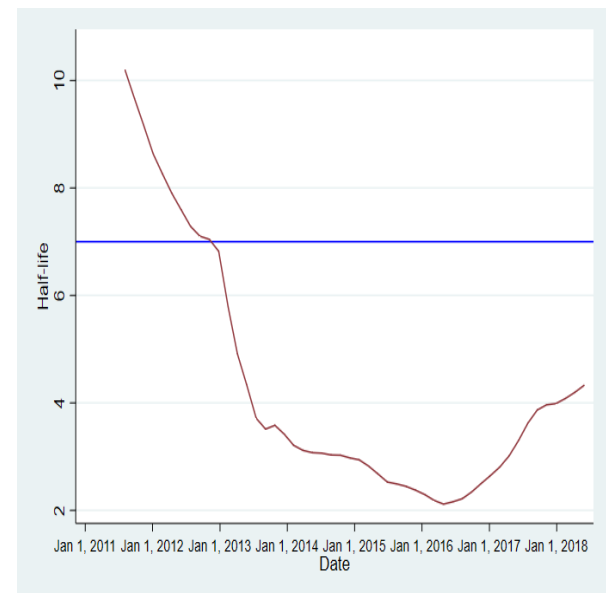

(c)

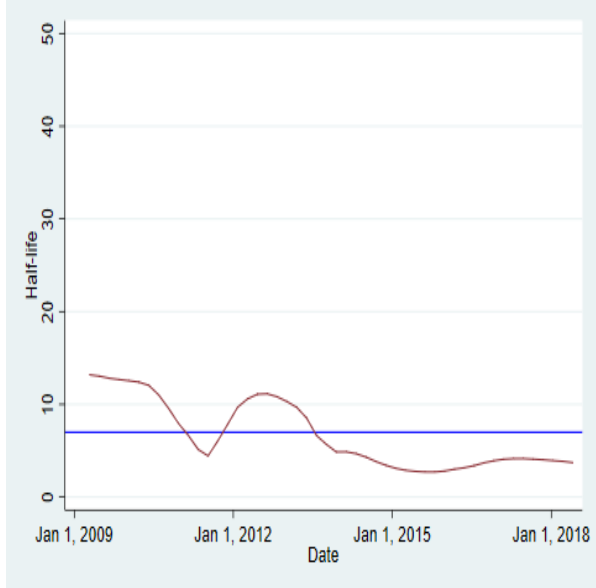

(b)

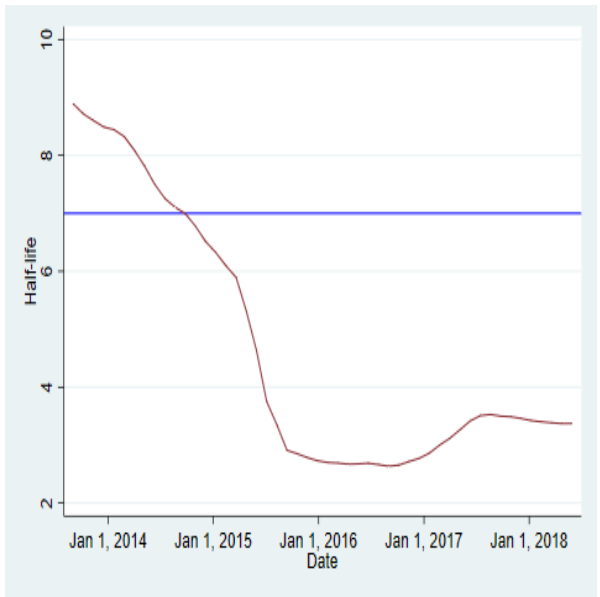

(d)

Figure A5. Dynamics of half-time for the BRVMC index using standard rolling regression. These graphs plot the half-time estimated using rolling regression. The date is the end date for a selected window. In (a), the half-time is 14 days using recursive rolling regression with a window whose end date is 1 July 2007. (a) Dynamics of half-time for the BRVMC index using standard rolling regression with a 2-year window; (b) Dynamics of half-time for the BRVMC index using standard rolling regression with a 4-year window; (c) Dynamics of half-time for the BRVMC index using standard rolling regression with a 6-year window; (d) Dynamics of half-time for the BRVMC index using standard rolling regression with an 8-year window. 


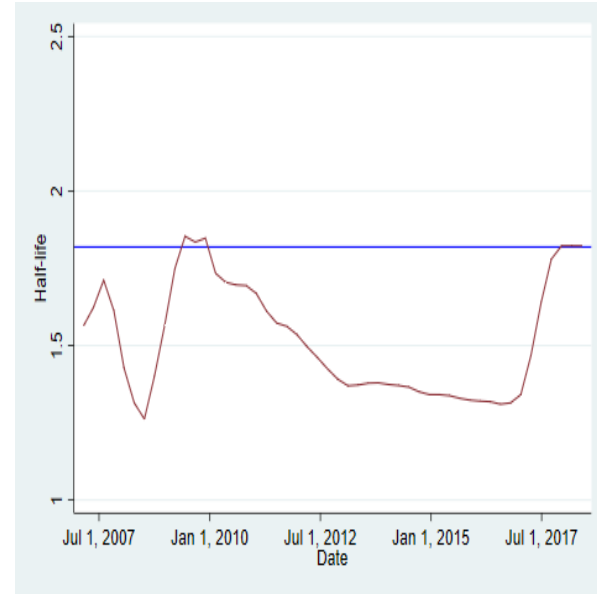

(a)

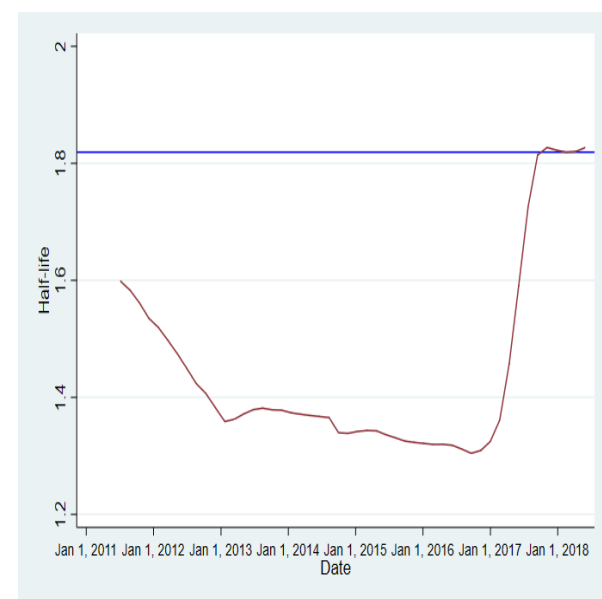

(c)

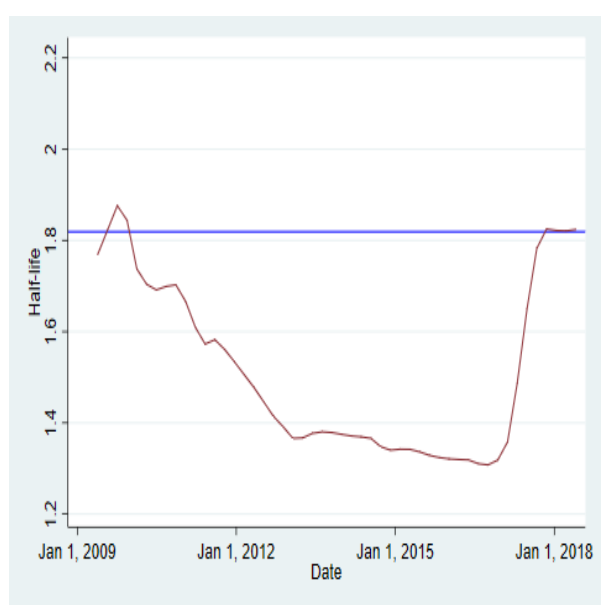

(b)

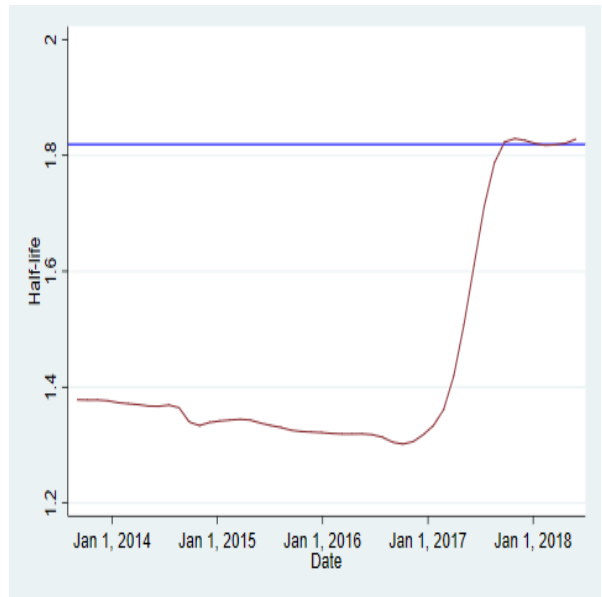

(d)

Figure A6. Dynamics of half-time for the BRVM10 index using recursive rolling regression. These graphs plot the half-time estimated using rolling regression. The date is the end date for a selected window. In (a), the half-time is 1.2 days using recursive rolling regression with a window whose end date is 1 July 2007. (a) Dynamics of half-time for the BRVM10 index using recursive rolling regression with a 2-year window; (b) Dynamics of half-time for the BRVM10 index using recursive rolling regression with a 4-year window; (c) Dynamics of half-time for the BRVM10 index using recursive rolling regression with a 6-year window; (d) Dynamics of half-time for the BRVM10 index using recursive rolling regression with an 8-year window. 


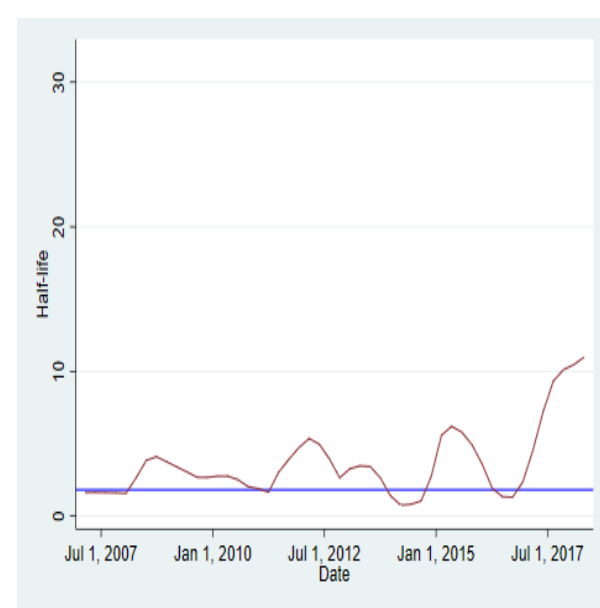

(a)

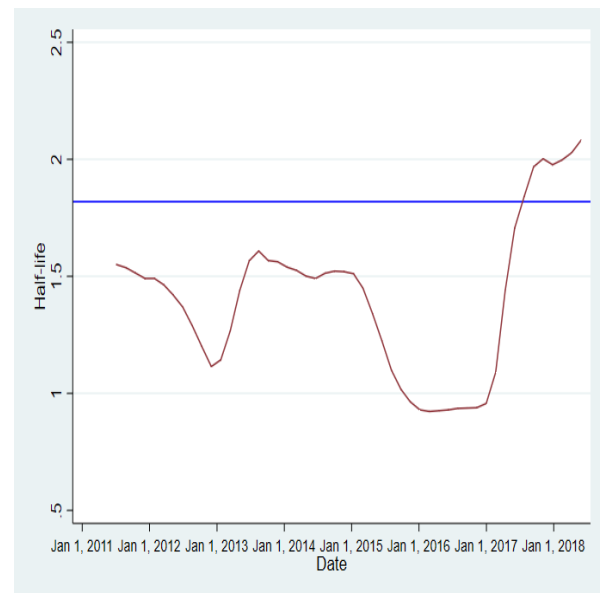

(c)

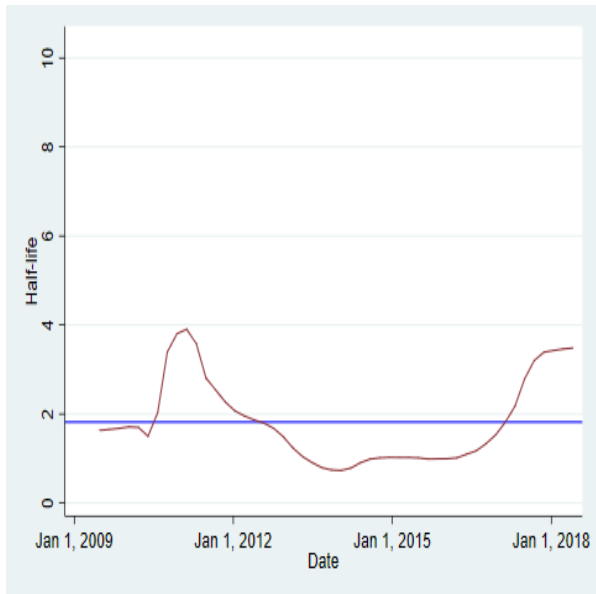

(b)

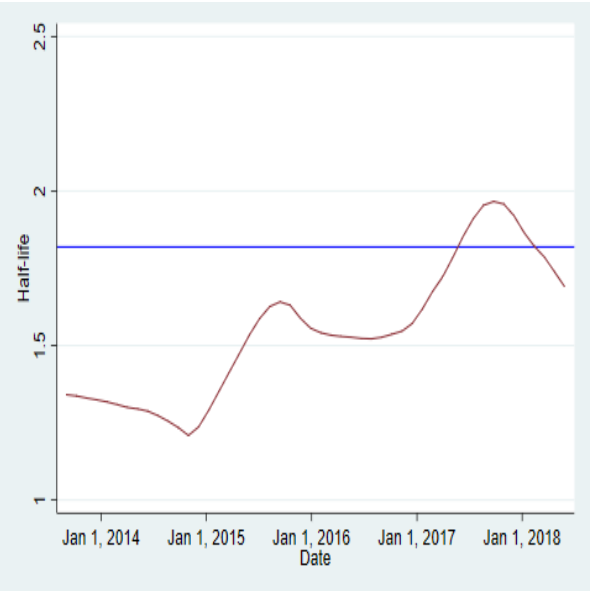

(d)

Figure A7. Dynamics of half-time for the BRVM10 index using standard rolling regression. These graphs plot the half-time estimated using rolling regression. The date is the end date for a selected window. In (a), the half-time is 1.4 days using recursive rolling regression with a window whose end date is 1 July 2007. (a) Dynamics of half-time for the BRVM10 index using standard rolling regression with a 2-year window; (b) Dynamics of half-time for the BRVM10 index using standard rolling regression with a 4-year window; (c) Dynamics of half-time for the BRVM10 index using standard rolling regression with a 6-year window; (d) Dynamics of half-time for the BRVM10 index using standard rolling regression with an 8-year window. 


\section{Appendix E. Dynamics of the Persistence Parameter in EGARCH}

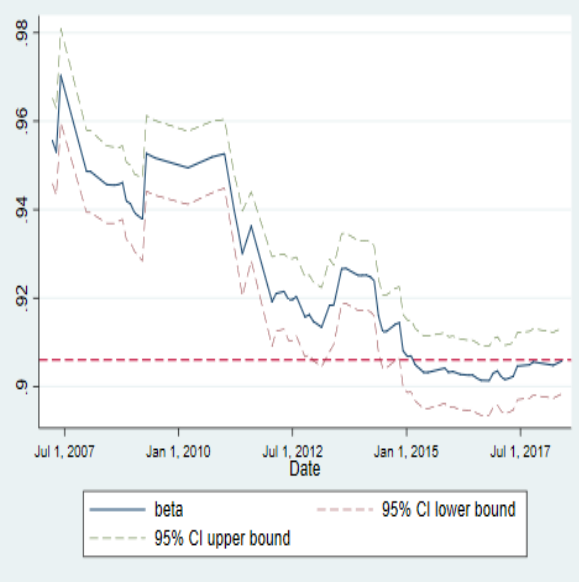

(a)

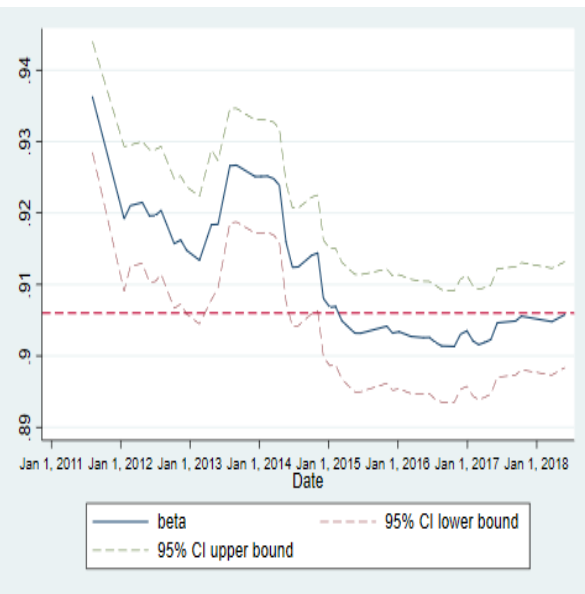

(c)

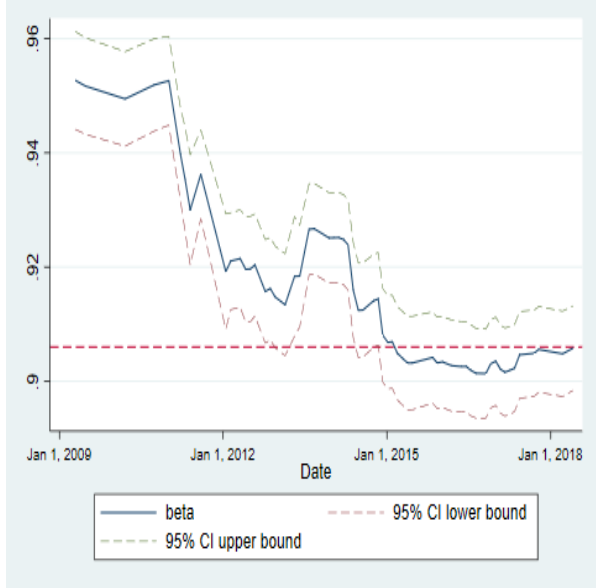

(b)

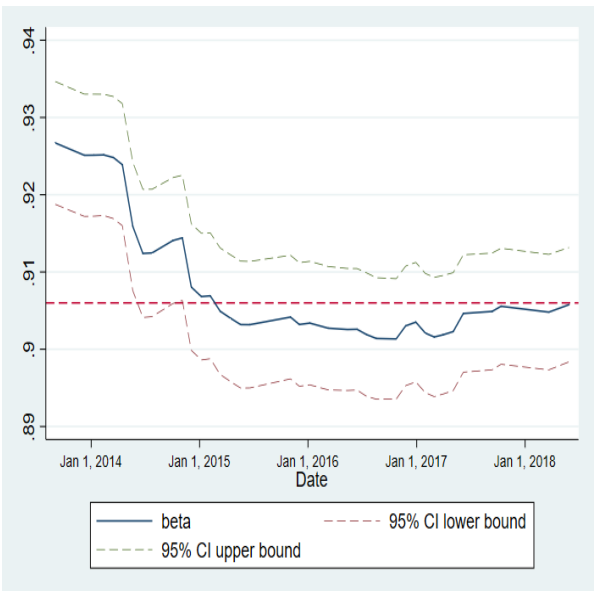

(d)

Figure A8. Dynamics of the persistence parameter for the BRVMC index using recursive rolling regression. These graphs plot the persistence parameter estimated using rolling regression. The date is the end date for a selected window. In (a), the persistence parameter is around 0.95 using recursive rolling regression with a window whose end date is 1 July 2007 . The dot lines denote the $95 \%$ level confidence interval. The persistence parameter declines slightly over the estimation period. This decrease in the persistence parameter can be considered an insight into the improvement of the efficiency of the market. (a) Dynamics of the persistence parameter using rolling regression with a 2-year window; (b) Dynamics of the persistence parameter using rolling regression with a 4-year window; (c) Dynamics of the persistence parameter using rolling regression with a 6-year window; (d) Dynamics of the persistence parameter using rolling regression with an 8-year window. 


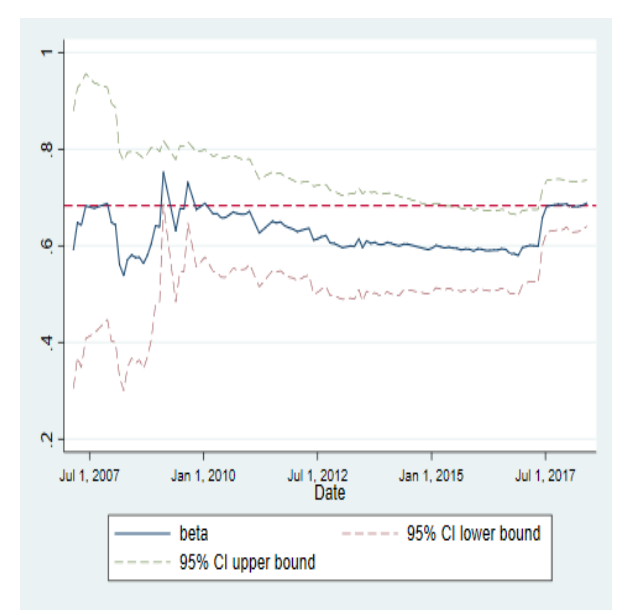

(a)

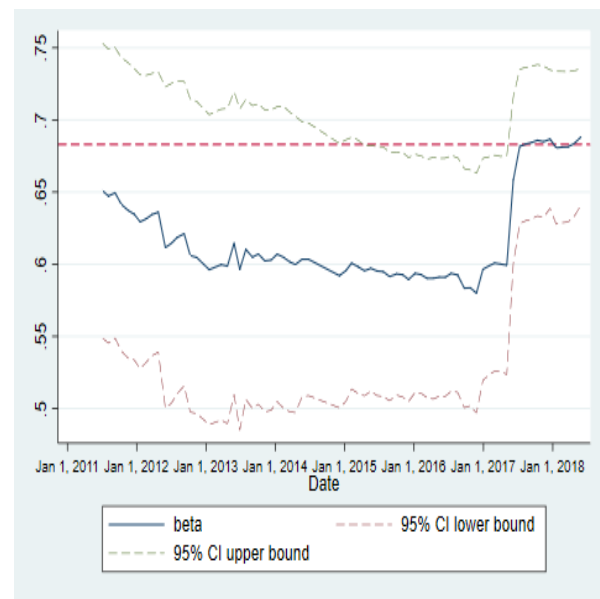

(c)

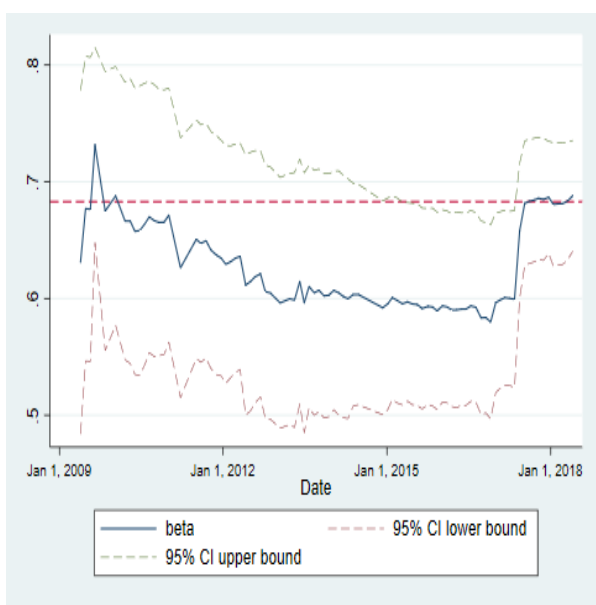

(b)



(d)

Figure A9. Dynamics of the persistence parameter for the BRVM10 index using recursive rolling regression. These graphs plot the persistence parameter estimated using rolling regression. The date is the end date for a selected window. In (a), the persistence parameter is around 0.6 using recursive rolling regression with a window whose end date is 1 July 2007. The dot lines denote the 95\% level confidence interval. (a) Dynamics of the persistence parameter using rolling regression with a 2-year window; (b) Dynamics of the persistence parameter using rolling regression with a 4-year window; (c) Dynamics of the persistence parameter using rolling regression with a 6-year window; (d) Dynamics of the persistence parameter using rolling regression with an 8-year window.

\section{References}

Ahmed, Rizwan Raheem, Jolita Vveinhardt, Dalia Streimikiene, and Zahid Ali Channar. 2018. Mean reversion in international markets: Evidence from GARCH and half-life volatility models. Economic Research-Ekonomska Istrăzivanja 31: 1198-217. [CrossRef]

Akaike, Hirotogu. 1998. Information theory and an extension of the maximum likelihood principle. In Selected Papers of Hirotugu Akaike. Berlin: Springer, pp. 199-213.

Anoruo, Emmanuel, and Luis Gil-Alana. 2011. Mean reversion and long memory in African stock market prices. Journal of Economics and Finance 35: 296-308. [CrossRef]

Bali, Turin G., and K. Ozgur Demirtas. 2007. Testing mean reversion in financial market volatility: Evidence from S\&P 500 index futures. The Journal of Futures Markets 28: 1-33. [CrossRef]

Bollerslev, Tim. 1986. Generalized autoregressive conditional heteroskedasticity. Journal of Econometrics 31: 307-27. [CrossRef] 
Corbet, Shaen, and Paraskevi Katsiampa. 2018. Asymmetric mean reversion of Bitcoin price returns. International Review of Financial Analysis In press. [CrossRef]

Dickey, David, and Wayne Fuller. 1981. Likelihood ratio statistics for autoregressive time series with a unit root. Econometrica: Journal of the Econometric Society 49: 1057-72. [CrossRef]

Engle, Robert. 1982. Autoregressive conditional heteroscedasticity with estimates of the variance of United Kingdom inflation. Econometrica: Journal of the Econometric Society 50: 987-1007. [CrossRef]

Engle, Robert. 2001. Garch 101: The use of arch/garch models in applied econometrics. Journal of Economic Perspectives 15: 157-68. [CrossRef]

Fama, Eugene. 1965. The behavior of stock-market prices. The Journal of Business 38: 34-105. [CrossRef]

Hannan, Edward, and Barry Quinn. 1979. The determination of the order of an autoregression. Journal of the Royal Statistical Society. Series B (Methodological) 41: 190-95. [CrossRef]

Kuttu, Saint. 2018. Asymmetric mean reversion and volatility in african real exchange rates. Journal of Economics and Finance 42: 575-90. [CrossRef]

Mlambo, Chipo, and Nicholas Biekpe. 2007. The efficient market hypothesis: Evidence from ten African stock markets. Investment Analysts Journal 36: 5-17. [CrossRef]

Nam, Kiseok, Chong Soo Pyun, and Stephen Avard. 2001. Asymmetric reverting behavior of short-horizon stock returns: An evidence of stock market overreaction. Journal of Banking $\mathcal{E}$ Finance 25: 807-24. [CrossRef]

Nam, Kiseok, Sei-Wan Kim, and Augustine C. Arize. 2006. Mean reversion of short-horizon stock returns: Asymmetry property. Review of Quantitative Finance and Accounting 26: 137-63. [CrossRef]

Narayan, Paresh, and Arti Prasad. 2007. Mean reversion in stock prices: New evidence from panel unit root tests for seventeen european countries. Economics Bulletin 3: 1-6.

Nelson, Daniel. 1991. Conditional heteroskedasticity in asset returns: A new approach. Econometrica: Journal of the Econometric Society 59: 347-70. [CrossRef]

Oikarinen, Elias, and Felix Schindler. 2015. Momentum and mean reversion in regional housing markets: Evidence from variance ratio tests. International Journal of Strategic Property Management 19: 220-34. [CrossRef]

Palwasha, Rana Imroze, Nawaz Ahmad, Rizwan Raheem Ahmed, Jolita Vveinhardt, and D. Štreimikienè. 2018. Speed of mean reversion: An empirical analysis of KSE, LSE and ISE indices. Technological and Economic Development of Economy 24: 1435-52. [CrossRef]

Poterba, James, and Lawrence Summers. 1988. Mean reversion in stock prices: Evidence and implications. Journal of Financial Economics 22: 27-59. [CrossRef]

Rapach, David, and Mark Wohar. 2006. Structural breaks and predictive regression models of aggregate US stock returns. Journal of Financial Econometrics 4: 238-74. [CrossRef]

Schwarz, Gideon. 1978. Estimating thedimension of a model. Annals Of statistics 6: 461-64. [CrossRef]

Spierdijk, Laura, Jacob Bikker, and Pieter Van den Hoek. 2012. Mean reversion in international stock markets: An empirical analysis of the 20th century. Journal of International Money and Finance 31: 228-49. [CrossRef]

Tie, Jingzhi, and Qing Zhang. 2016. An optimal mean-reversion trading rule under a Markov chain model. Mathematical Control and Related Fields 6: 467-88. [CrossRef]

$\mathrm{Wu}, \mathrm{Yi}$, and Nicole Lux. 2018. U.K. house prices: Bubbles or market efficiency? evidence from regional analysis. Journal of Risk and Financial Management 11: 54. [CrossRef]

(C) 2019 by the authors. Licensee MDPI, Basel, Switzerland. This article is an open access article distributed under the terms and conditions of the Creative Commons Attribution (CC BY) license (http://creativecommons.org/licenses/by/4.0/). 